\title{
International Commission on Radiation Units and Measurements
}

National Cancer Institute

\section{Source}

National Cancer Institute. International Commission on Radiation Units and

Measurements. NCI Thesaurus. Code C43966.

The International Commission on Radiation Units and Measurements (ICRU) was established in 1925 by the International Congress of Radiology. Since its inception, it has had as its principal objective the development of internationally acceptable recommendations regarding (1) quantities and units of radiation and radioactivity; (2) procedures suitable for the measurement and application of these quantities in diagnostic radiology, radiation therapy, radiation biology, and industrial operations; and (3) physical data needed in the application of these procedures, the use of which tends to assure uniformity in reporting. The ICRU endeavors to collect and evaluate the latest data and information pertinent to the problems of radiation measurement and dosimetry, and to recommend in its publications the most acceptable values and techniques for current use. 